\title{
Discussion on the Continuing Education of Accounting Based on the Network Environment
}

\author{
Nana Huang \\ Chengdu Normal University, Chengdu Sichuan, 611130, China
}

Keywords: Network Environment, Accounting, Continuing Education.

\begin{abstract}
With the advent of the Internet age, the traditional accounting information processing mode has been unable to meet the needs of the development of the current era. If the accountants who have been accustomed to the traditional way of accounting education can not enhance the professional ability of individuals, it is difficult to promote the reasonable disposal of accounting information. In view of this, it is very important to do a good job of continuing education of the accounting workers under network environment. In this paper, we discussed the common model of accounting continuing education, listed the outstanding advantages of accounting continuing education under the network environment, analyzed the questions existing in current accounting continuing education, and proposed the countermeasure based on the network environment to strengthen the continuing education of accounting.
\end{abstract}

\section{Introduction}

Provisions on the Continuing Education of Accounting Workers issued by the Ministry of Finance clearly states that accounting workers have the rights and obligations of continuing education, and makes definitive provisions on how to further improve moral and professional quality of accounting workers. In the past, the continuing education of China's accounting workers is usually conducted on face to face bases. However, due to the rapid development of modern computer technology, especially the modern network technology, the implementation of continuing education of accounting personnel through the use of network technology is becoming more and more common. The form of the continuing education is not only reflected in a more advanced technology, but also in the reform of educational concept, educational method and educational content. Although the network continuing education of accounting workers in our country is still in the stage of popularization and application, it has become an inevitable development trend, which is worth a in-depth study for the researchers in the accounting field.

\section{The common model of accounting continuing education}

According to the continuing education regulations formulated by the Ministry of Finance, the continuing education of accounting workers takes training as the main body, while on-job self-studying as an effective supplement to continuing education. The mode of accounting continuing education usually includes the following two: one is the traditional education mode, which mainly takes a face-to-face method. The accountants can participate in the finance and accounting training arranged by continuing education institutions which are licensed and released by the competent department of continuing education. The training is often conducted on face to face bases, after the learning reaches the required time, financial personnel should be organized to participate in the examination. That is the so-called traditional continuing education mode which provides a good opportunity for the exchange of financial personnel, and strengthens the management for the financial sector. However, more and more training institutions do not concern about the investment of training funds, resulting in a low overall quality of training courses and teachers quality, but also causing that accounting workers have a feel that there is no practical use to attend the lectures. If payment is the best and simplest approach to pass the examination, so that the model becomes increasingly superficial form, which makes it difficult to play a role in enhancing the quality of accounting workers. Second is the innovation model of continuing education, which mainly refers to the network, 
remote and audio-visual education vigorously promoted by the financial departments, aiming at using information technology to enhance continuing education effect of accountants, in which due to the continuous development of Internet technology, the network educational mode has developed as a very important form of education. Network education refers to that under the teacher's positive guidance, the students use computer networks and other technologies to obtain the corresponding information resources, and implements new education by the use of effective ways. The process of Network education model is to spread the corresponding knowledge by the use of the network, to achieve the purpose of education. The form of network education is a kind of interaction between man and machine, which has been welcomed by more and more accounting continuing education students. Because of the further development of the network education model, the innovation education model will inevitably become a trend of the accounting personnel to continue education.

\section{The outstanding advantages of accounting continuing education under the network environment}

First, Convenience. The application of network technology leads to the update of accountants continuing education method from the original passive learning to active learning, promoting the all-round development of accounting continuing education to be a lifelong education system for accounting workers. Network can provide a better development platform for accounting workers, and all kinds of new courses can be very good to meet the needs of the accounting workers for continuing education, so as to provide better conditions for their learning. Under the network era, accounting workers can break through the limitations of traditional education mode for space and time in the process of continuing education, thereby to form the concept of independent learning, to better play the flexibility of continuing education. Choosing the time and content of the study according to their own situation, the accounting workers can study at any time, and adjust the learning plan according to the actual situation. Second, Economy. In the era of network, accountants' continuing education does not require the implementation of training in large-scale, but only need accountants to be registered on the web site specified by financial sector. In this way it can receive training in the stipulated time, and obtain reasonable credits after passing the relevant assessment, so as to save the costs of manpower and material resources. Three, Break through the restriction of time and space. The application of network technology in the continuing education of accounting personnel has already broken through the traditional teaching mode, which effectively shortens the time and space in the education process. For accounting workers, the continuing education of accounting workers under the network environment not only has the convenience, but also not subject to the restrictions of time and space, units and positions. The accountants who participate in continuing education training can select some content to learn according to the actual need. In this way, they will have the opportunity to listen to the famous financial management experts and professors, so as to further accelerate the updating and propagation velocity of financial accounting knowledge. Of course, there are quite a number of courses in the network to better meet the various levels of financial workers for continuing education, which gets rid of the mandatory arrangements in the implementation of the traditional continuing education.

\section{The problems existing in current accounting continuing education}

First, the lack of the concept of continuing education caused by the incomplete understanding. The implementation of continuing education for the unit accounting workers is suitable for the accounting standards, rules and regulations and the actual needs of economic development under the new situation of the network era. However, now many managers lack a deep understanding of the accounting continuing education, and a large number of accounting workers themselves have a feeling that there is no need to continue to learn new knowledge and skills in the financial sector. It is because there is a deviation in understanding that causes a stagnant situation in accounting continuing education. 
Second, An urgent need to improve the quality of teachers. In the continuing education of accounting, professional accounting continuing education teachers are extremely limited, and the training ground is often temporary rental and the required training facilities are very simple, especially that the training of teachers is very unstable, and some training teachers are from the temporary recruitment of the current agencies, so naturally there will be some problems like some teachers with not enough solid professional knowledge, the lack of unified planning in the training materials of continuing education, which causes that the accounting knowledge taught by teachers is too theoretical and lacks practical content, so the content of the training is too single, which affects the improvement of actual skill level of the workers.

Third, the limitations existing in the content of the accounting continuing education curriculum. It is rare for some units to implement the differentiated continuing education for the accounting staffs based on different titles, but according to a unified program. The ignorance of the differences between practitioners, results the lack of enough flexibility in continued education, and can not well meet the actual needs of different levels of accountants, causing that the curriculum content of continuing education is difficult to meet the actual needs to enhance the operational capacity for high quality of accounting personnel, at the same time, the persons with relatively poor ability will have a feeling that I don't understand or I do not want to continue to study the idea, thereby affecting the effectiveness of continuing education of the accounting workers.

Forth, the lagged evaluation means and methods. In the network era, the implementation of professional training for accounting workers needs standardized evaluation, so as to enhance the effectiveness of continuing education and training. However, now many accounting continuing education and training just scratch the surface, while evaluation methods and means have become obsolete and evaluation is also limited to the written records of training time, place and content. The implementation of highly quantitative assessment on the practical effect of training causes that a lot of accounting workers of continuing education do not pay attention to evaluation, which leads to the low learning effectiveness and high time cost.

\section{The countermeasures to strengthen the accounting continuing education based on the network environment}

\section{Promote the ideological consciousness and create a high quality of network learning environment.}

In the implementation of continuing education for accountants, first of all, the units should be fully aware of the importance of education and training, thereby increasing the strengths on continuing education, actively encouraging financial personnel to participate in the continuing education training. At the same time, all managers should integrate the updating of the professional knowledge of accounting workers into the human resource management system, and comprehensively combine the continuing education of accounting personnel with the sustainable development of the unit, to strengthen the planning. Further efforts on the organization and creation of internal environment forms a better learning environment for the implementation of the continuous education of accounting workers. According to the practical experience, the comprehensive use of network means help the accounting personnel to carry out continuing education. In the network environment, the implementation of continuing education for accounting workers will be able to make up the deficiency of the current accounting continuing education work station. Naturally, the teaching in the network environment can operate independently, so as to maximize the effect. When using the network teaching method in the continuing education and training, it is necessary to give full consideration to the accounting practitioners, continuing education and training resources, the implementation form, performance evaluation and other related elements, and use network to develop the continuing education and training.

\section{Strengthen the teacher talent allocation of continuing education.}

Nowadays, the continuing education and training of accounting personnel have long been thwarted by the extreme lack of accounting teacher talents, unprofessional teachers, and the lack of practicalness. All of these are in violation of the principles for further education. At the same time, the 
lack of training venues is also an important factor which affects the effectiveness of continuing education and training. So as to perfect teacher talent configuration of accounting continuing education, select immobilized training venues, improve the training facilities and equipment, fully use the advantage of network era, and implement a full range of network teaching, so as to better adapt to the learning need of accounting workers in different time periods and different age, thus to achieve the best learning results. Although the teacher staff is one of the external training conditions, but also the important driving force to enhance the professional quality of accounting workers. Strengthening the teacher staff of accounting continuing education, can not only enhance the quality of accounting continuing education, but also make the learning researchers better learn the latest accounting knowledge and skills in a shorter time.

\section{Positively innovate the course content of online accounting continuing education and training.}

In the implementation of continuing education and training for the unit accounting workers, it needs the cooperation of relevant departments of the enterprise, and to develop a reasonable accounting standards. To be committed to innovate the related content of accounting continuing education network teaching, and effectively improve the accounting continuing education skills and pertinence. In the process of the implementing network teaching, it is necessary to combine the related theories of financial accounting education according to the quality situation, job requirements of accounting workstation in all levels to integrate the training content, and clear the improvement direction of professional skills of accountants in all different grades. It must combine the needs of different occupations, and clear the content and way of continuing education and training. On the basis of this, according to different types like senior, intermediate and primary accounting, implementing the training content, of course, it also can implement the classification according to the different financial positions of accounting practitioners, and work out the content of education and training, to really meet the needs of all parties on the ground.

\section{Create a reasonable evaluation mechanism of accounting continuing education.}

In the implementation of continuing education for the accounting practitioners, we should have a real understanding of the effectiveness of its training. In view of this, we must form a reasonable evaluation mechanism of continuing education, which is very important for education and training. Sound and perfect training mechanism of education evaluation can not only implement the overall planning for the effect of education, but also carry out comprehensive and objective analysis of the training content to understand that whether it can meet the development requirements of the current era, whether it can satisfy the practical educational needs of accounting personnel, or whether it has a very good practical value. The accounting continuing education and training is truly meaningful only if grasping the situation, and the future training work can be more targeted.

\section{Summary}

In summary, it has an important value on the promotion of the sustainable development of the unit to strengthen the continuing education of accounting workers in network era. Accounting continuing education under the network environment can be said to be both opportunities and challenges, which tests the effectiveness and progress of the accounting education work. So, the management unit or the general accounting workers shall earnestly maintain more sober mind, continuously improve their awareness of this, adopt a rational and calm attitude to treat the continuing education work in network era. On this basis, we should actively seize the opportunities to use network teaching means more on the accountants continuing education, and continue to perfect the education management mechanism, improve the effectiveness of network education, give full play to the Internet in the continuing education of accounting workers and promote the new development of unit financial work.

\section{References}

[1] Yan Jin, Liu Shuzhen. Application of network teaching in the continuing education of accounting practitioners, Continuing education research,2009(1). 
[2] Xie Long.The current situation and improvement suggestions on the network continuing education of accounting in Chongqing, Business accounting, 2013(8) .

[3] Wan Lishun. Research on the continuing education of accounting practitioners, Net World, 2014(15).

[4] Wang Shuling. Investigation on the continuing education of accounting practitioners in less developed areas--Take West Yunnan as an example, Assets and finances, 2014(18).

[5] Zhao Zhihong. Discussion on the network continuing education of accounting based on user requirements, Chinese adult education, 2014(18). 